\title{
Stevioside induced cytotoxicity in colon cancer cells via reactive oxygen species and mitogen-activated protein kinase signaling pathways-mediated apoptosis
}

\author{
HAI-PENG REN ${ }^{1}$, XIAO-YAN YIN ${ }^{2}$, HAI-YING YU ${ }^{1}$ and HAI-FENG XIAO ${ }^{1}$ \\ ${ }^{1}$ Department of Oncology, Weifang People's Hospital of Shandong Province, Weifang, Shandong 261041; \\ ${ }^{2}$ Weifang Kuiwen District Family Planning of Health Inspection Team, Weifang, Shandong 261041, P.R. China
}

Received January 29, 2016; Accepted December 20, 2016

DOI: $10.3892 / \mathrm{ol} .2017 .5744$

\begin{abstract}
The role of mitogen-activated protein kinase (MAPK) signaling pathways in cell growth and differentiation has been well established. The present study aimed to investigate the anti-proliferative effect of stevioside on human colon cancer HT-29 cells. Additionally, the effect of stevioside on cell cycle arrest and MAPK signaling pathways in HT-29 cells was explored. Stevioside was observed to significantly inhibit cancer cell growth at a dose of $5 \mu \mathrm{M}$ at 48 and 72 h. A dose-dependent increase in the apoptosis rate was observed with cell cycle arrest at $\mathrm{G} 2 / \mathrm{M}$ phase. In addition, caspase- 9 and caspase- 3 activity also increased. An increase in reactive oxygen species (ROS) production and a decrease in the mitochondrial membrane potential indicated that the mitochondrial-mediated intrinsic pathway is responsible for apoptotic activity. These results were additionally verified by the elevated expression level of phosphorylated p38 and extracellular signal-regulated kinase mitogen-activated protein kinases (MAPKs). Additionally, by inhibiting ROS production and MAPK activation, the antiproliferative effect of stevioside was suppressed, confirming the hypothesis that ROS and MAPK proteins induce apoptosis in human colon cancer HT-29 cells.
\end{abstract}

\section{Introduction}

Colon cancer ranks third among all type of cancers with respect to global mortality (1). Due to poor responsiveness against currently available chemotherapeutic drugs and side effects, the treatment of colon cancer requires the use of natural therapeutic agents $(2,3)$. Several natural compounds

Correspondence to: Dr Hai-Peng Ren, Department of Oncology, Weifang People's Hospital of Shandong Province, 151 Wenhua Street, Kuiwen, Weifang, Shandong 261041, P.R. China

E-mail: renhaipengyh@hotmail.com

Key words: colon cancer, apoptosis, growth inhibition, reactive oxygen species, mitogen-activated protein kinase have been previously investigated against colon cancer cell lines such as nobiletin (4) and arctigenin (5). Herbs are well known for their medicinal properties due to the presence of natural components within them. Stevioside has been investigated among such natural medicinal agents (6).

Stevioside, a diterpenoid glycoside, comprises of steviol, an aglycone, and glucose molecules, and is isolated from Stevia rebaudiana (Fig. 1). This small shrub is a member of the genus Stevia of the Asteraceae family and is commonly known as sugar leaf. Although this shrub is native to Brazil and Paraguay, at present it is cultivated in various countries of the world including East Asian countries, the United States of America, Canada and Europe (7-9). As stevioside is 300 times sweeter than sucrose and contains numerous medicinal properties against diabetes mellitus, hypertension and obesity, it is used in the food, cosmetics and pharmaceutical industries (10-12). Natural products have been well known to exhibit anti-cancer activity through apoptosis as a major molecular phenomenon (13). Apoptosis is programmed cell death that maintains the cellular balance. If this balance is disturbed this leads to uncontrolled cell growth. Thus, the discovery of novel anticancer therapeutics largely focuses on apoptosis-stimulating agents in the cell via various pathways. One of these well-recognized molecular pathways leading to apoptosis is the production of excessive reactive oxygen species (ROS) (14).

Normal cells tend to produce ROS constantly, which is counteracted by the available antioxidant protein in the cells (15). However, if ROS production exceeds the limit of counteraction it causes a state of oxidative stress. Such states of oxidative stress can be a consequence of various diseases including cancer (16). ROS regulates several signaling pathways, which are involved in the normal functioning of the cell. Therefore, altered ROS levels can lead to the impaired functioning of the cellular processes. One of the most well-studied signaling pathways regulated by ROS is the mitogen-activated protein kinase pathway (MAPK) (17). Extracellular signal-related kinases (ERK), c-Jun amino-terminal kinases (JNK) and phosphorylated P-38 (p-p38) are 3 well-known subgroups of the MAPK family that are involved in cell growth and cell death, and are activated by a cascade of phosphorylation (18). 
A previous study demonstrated that stevioside induces ROS-mediated apoptosis in breast cancer cell lines (19). However, the role of stevioside in inducing ROS-mediated apoptosis in colon cancer cells remains unknown. Therefore, the present study aimed to reveal the ROS-mediated apoptotic phenomenon of the stevioside-induced antiproliferative effect on human colon cancer HT-29/HCT-15 cells. Also, the involvement of ERK and P-38 MAPK in inducing antiproliferative effect was assessed.

\section{Materials and methods}

Chemicals. Stevioside hydrate (purity $\geq 98 \%$ ), fetal bovine serum (FBS), MTT, propidium iodide and SDS were purchased from Sigma-Aldrich; Merck Millipore, Darmstadt, Germany. The medium for the cell culture RPMI 1640 and Dulbecco's modified Eagle's medium (DMEM) medium were purchased from Invitrogen; Thermo Fisher Scientific, Inc. Waltham, MA, USA. The supplements for the cell culture media such as penicillin, streptomycin and L-glutamine were obtained from Lonza Group AG, Basel, Switzerland. The fluorescent dyes 2',7'-dichlorofluorescin diacetate $\left(\mathrm{H}_{2} \mathrm{DCF}-\mathrm{DA}\right)$ and 3,3'-dihexyloxacarbocyanine iodide $\left(\mathrm{DiOC}_{6}(3)\right)$ were purchased from Thermo Fisher Scientific, Inc. To determine the signaling pathways involved, the ROS scavenger N-acetyl-L-cysteine (NAC) and the MAPK inhibitor hydrochloride4-(4-Fluorophenyl)-2-(4-methylsul finylphenyl)-5-(4-pyridyl) $1 \mathrm{H}$-imidazole (SB203580) were purchased from Sigma-Aldrich; Merck Millipore, while the ERK inhibitor 2'-amino-3'-methoxyflavone (PD98059) was obtained from Calbiochem; Merck Millipore. The primary antibodies directed against p-p38 (cat. no. sc-166182), pERK (cat. no. sc-7383) and $\beta$-actin (cat. no. sc-130656), and the horseradish peroxidase (HRP) labelled rabbit anti-mouse secondary antibody (cat. no. sc-2357) were purchased from Santa Cruz Biotechnology, Inc. (Dallas, TX, USA). Primary antibodies were used at dilution 1:1,000 and secondary antibodies were used at dilution 1:10,000.

Cell culture. Stock solution of $50 \mathrm{mM}$ stevioside hydrate was prepared using dimethyl sulfoxide (DMSO). HT-29 was used as the human colon carcinoma cell line for the present study, which was cultured in RPMI 1640 medium supplemented with $10 \% \mathrm{FBS}, 100 \mathrm{U} / \mathrm{ml}$ penicillin, $100 \mu \mathrm{g} / \mathrm{ml}$ streptomycin and $2 \mathrm{mM}$ L-glutamine. The HT-29 cells were cultured at $37^{\circ} \mathrm{C}$ in a humidified chamber air and $\mathrm{CO}_{2}(95$ and $5 \%$, respectively) and were maintained at $\sim 90 \%$ confluence level.

Effect of stevioside on HT-29 cell viability. The antiproliferative activity of stevioside on colon cancer HT-29 cell line was studied using an MTT assay. Initially, in a 96-well plate, $2 \times 10^{4}$ cells/well were cultured for $24 \mathrm{~h}$ at $37^{\circ} \mathrm{C}$ and subsequently treated with different doses, $0.5,1,2.5$ and $5 \mu \mathrm{M}$, of stevioside for 24,48 and $72 \mathrm{~h}$. Subsequent to the respective incubation times, the treated cells were added to MTT solution for $3 \mathrm{~h}$ at $37^{\circ} \mathrm{C}$. Subsequent to the completion of the reaction time, medium along with MTT reagent was discarded and cells were lysed in DMSO to record the optical density at $570 \mathrm{~nm}$ for the production of mitochondrial succinate-mediated MTT formazan, a cell viability indicator. The experiments were conducted in triplicate for accuracy and results are expressed as the mean \pm standard deviation.

Effect of stevioside on HT-29 cell cytotoxicity. To determine the cell cytotoxicity of stevioside, the production of lactate dehydrogenase (LDH) within damaged cells was used as marker using a cytotoxicity detection kit (Takara Bio Inc., Otsu, Japan). A total of $2 \times 10^{4}$ HT- 29 cells per well were seeded in a $96-w e l l$ plate and incubated at $37^{\circ} \mathrm{C}$ for $24 \mathrm{~h}$. Subsequent to the incubation time the seeded cells were treated with stevioside at different concentrations, $0.5,1,2.5$ and $5 \mu \mathrm{M}$, for varying times; 24, 48 and $72 \mathrm{~h}$. PBS (40 $\mu \mathrm{l})$ and the reaction mixture provided in the cytotoxicity detection kit $(50 \mu \mathrm{l})$ were added to the cell free culture medium samples $(10 \mu \mathrm{l})$ in 96 -well plates and incubated in the dark at $25^{\circ} \mathrm{C}$. Subsequent to the reaction time (45 $\mathrm{min})$, stop solution $(50 \mu \mathrm{l})$ was added and cell cytotoxicity was calculated by measuring the optical density at $490 \mathrm{~nm}$ wavelength.

Effect of stevioside on apoptosis and cell cycle distribution. The apoptotic effect of stevioside on the HT-29 cells at different concentrations was determined via a FACScan flow cytometer (BD Biosciences, San Jose, CA, USA). A total of 50,000 cells/well were seeded in a 6 -well culture plate and incubated for $24 \mathrm{~h}$ at $37^{\circ} \mathrm{C}$ in $10 \%$ FBS-supplemented DMEM medium. The adherent cells were treated with $0.5,1,2.5$ and $5 \mu \mathrm{M}$ stevioside for $48 \mathrm{~h}$. Following treatment, the samples were centrifuged $\left(45 \times \mathrm{g}\right.$ for $5 \mathrm{~min}$ at $4^{\circ} \mathrm{C}$ ) and the pellets were collected, fixed and washed. Pelleted cells were then treated with $1 \%$ volume/volume Triton X-100 and incubated at $37^{\circ} \mathrm{C}$ for $10 \mathrm{~min}$. To stain the DNA, the cells were mixed with $50 \mu \mathrm{g} / \mathrm{ml}$ propidium iodide solution at $4^{\circ} \mathrm{C}$. Apoptotic rate and cell cycle phase distribution were further analyzed using a FACScan flow cytometer.

Effect of stevioside on caspase activity. A caspase-3 and caspase-9 colorimetric assay kit (BioVision, Inc., Milpitas, CA, USA) was used to confirm the apoptotic effect of stevioside on the HT-29 cells, according to protocol of the manufacturer. Following stevioside treatment at varying concentrations, the HT-29 cells were incubated for $48 \mathrm{~h}$ and centrifuged at $12,000 \times \mathrm{g}$ for $10 \mathrm{~min}$ followed by cell collection as pellets. The cells were additionally re-suspended in ice-cold lysis buffer for $10 \mathrm{~min}$ and centrifuged at $10,000 \times \mathrm{g}$ for $1 \mathrm{~min}$ to collect supernatant. Equal amounts of protein, $200 \mu \mathrm{g}$, were then added to the respective substrates in reaction buffer and incubated at $37^{\circ} \mathrm{C}$ for $30 \mathrm{~min}$. Finally, an ELISA microplate reader was used to measure the released p-nitroaniline quantity at $400 \mathrm{~nm}$.

Effect of stevioside on ROS production. A total of $2 \times 10^{5}$ HT-29 cells were cultured per well in a 12 -well plate. Subject to reaching confluency, the cells were treated with predetermined concentrations of stevioside and incubated for $48 \mathrm{~h}$ at $37^{\circ} \mathrm{C}$. Following incubation, the cells were collected subsequent to centrifugation $\left(45 \mathrm{x} \mathrm{g}\right.$ for $10 \mathrm{~min}$ at $4^{\circ} \mathrm{C}$ ) as a pellet and washed thoroughly using PBS. Furthermore, the cells were added to a fluorescent probe, $\mathrm{H}_{2} \mathrm{DCF}$-DA, at room temperature in the dark for $20 \mathrm{~min}$. A FACScan flow cytometer at $480 \mathrm{~nm}$ and $525 \mathrm{~nm}$ (excitation and emission 
wavelengths, respectively) was used to analyze the stained cells (20).

Effect of stevioside on mitochondrial membrane potential $(\Delta \Psi m)$ level. The HT-29 cells were prepared and treated with stevioside in a similar manner as aforementioned. Subsequent to collecting the cells as pellets, the cells were stained with $\mathrm{DiOC}_{6}(3)$ and analyzed by flow cytometry as discussed previously (21).

Western blot analysis. Cellular protein was collected from the HT-29 human colon cancer cells subsequent to treatment with stevioside at various concentrations for $48 \mathrm{~h}$. The cells were then treated with lysis buffer followed by centrifugation at $6,400 \times \mathrm{g}$ for $30 \mathrm{~min}$ at $4^{\circ} \mathrm{C}$. A protein assay reagent kit (Bio-Rad Laboratories, Inc., Hercules, CA, USA) was then used to estimate the total amount of protein in the collected supernatant. Furthermore, the expression levels of p-p38 and pERK were estimated by first separating proteins by western blot analysis using SDS-PAGE, according to a protocol of a previous study, with slight modifications (22). The gel was then transferred electrophoretically to a nitrocellulose membrane, followed by membrane treatment with the primary antibodies of $\mathrm{p}$-p38, pERK and $\beta$-actin. Following overnight incubation at $4^{\circ} \mathrm{C}$, the membranes were then treated with HRP conjugated secondary antibodies specific to primary antibodies for $1 \mathrm{~h}$ at room temperature. The protein bands were then visualized using an enhanced chemiluminescence detection system (FUJIFILM LAS-3000 mini, Tokyo, Japan).

Inhibition of MAPK signaling pathway. THE HT-29 cells were plated in 48 -well culture dish at a density of $3.5 \times 10^{4}$ cells/well and pre-incubated at $37^{\circ} \mathrm{C}$ with $10 \mu \mathrm{M}$ of the MAPK inhibitor, SB203580, the ERK inhibitor, PD98059, or the ROS scavenger, NAC, for $2 \mathrm{~h}$, followed by treatment with $5 \mu \mathrm{M}$ stevioside to analyze the effect of the inhibitors on stevioside-induced antiproliferation. Furthermore, HT-29 cell viability was studied using MTT assay, as will be described subsequently.

Statistical analysis. An unpaired two-tailed Student's $t$ test and Prism software (version 5; GraphPad Software, Inc., La Jolla, CA, USA), were used to obtain and evaluate the statistical data. $\mathrm{P}<0.05$ was considered to indicate a statistically significant difference.

\section{Results}

Stevioside inhibited proliferation of HT-29 cells. In the present study, to investigate the growth inhibitory effect of stevioside on the colon carcinoma HT-29 cell line, an MTT assay was performed subsequent to 24,48 and $72 \mathrm{~h}$ of treatment at various doses. Fig. 2A presents the dose-dependent cell growth inhibition by stevioside on the HT-29 cells at all the aforementioned time points studied. With respect to cell viability, $\sim 60-70 \%$ inhibition of HT-29 cells was observed between 48 and $72 \mathrm{~h}$ of stevioside treatment at a dose of $5 \mu \mathrm{M}$, which was considered significant $(\mathrm{P}<0.05)$. In addition, similar results were obtained by LDH assay (Fig. 2B), showing dose-dependent cytotoxicity on HT-29 cells by

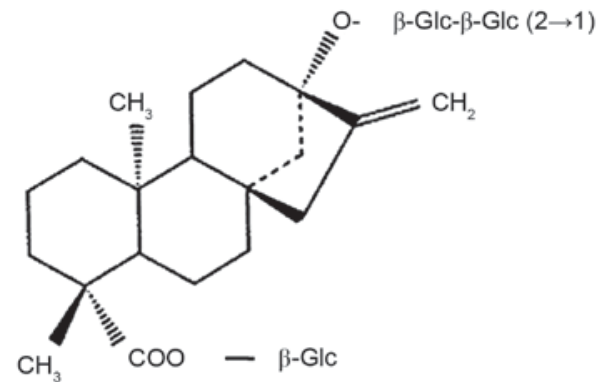

Figure 1. Structure of stevioside.
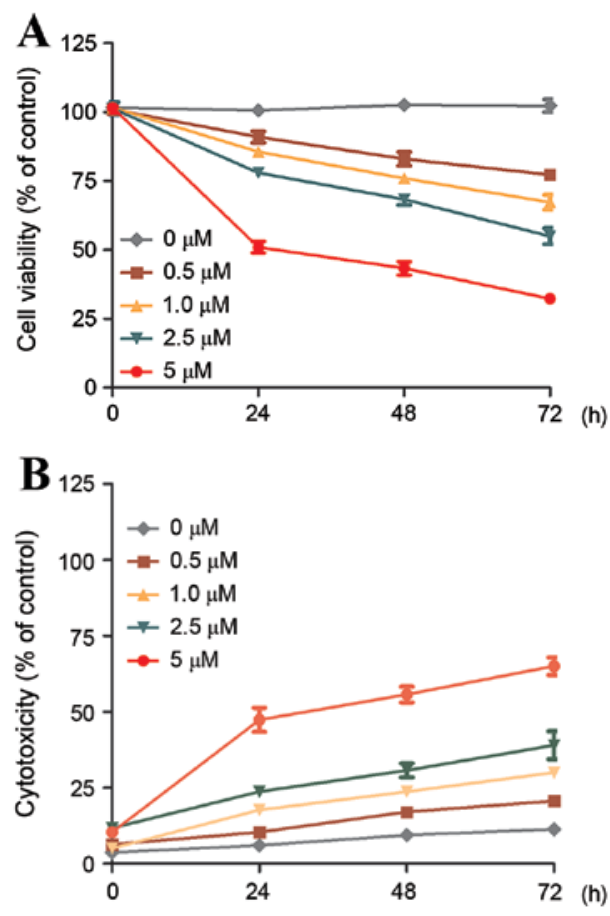

Figure 2. Cell growth inhibition of stevioside on HT-29 colon cancer cells (A) MTT assay, (B) LDH assay. LDH, lactate dehydrogenase.

stevioside. Therefore, for additional experiments $48 \mathrm{~h}$ was selected as a significant time point for showing anti-proliferative effect.

Stevioside induced apoptotic effects and cell cycle arrest in HT-29 cells. The present study then assessed the involvement of apoptosis in the antiproliferative effect of stevioside on HT-29 cells using flow cytometry subsequent to $48 \mathrm{~h}$ of treatment. Stevioside treatment was observed to increase the apoptotic rate of HT-29 cells in a dose-dependent manner, with a maximum observed rate of $24.15 \pm 1.56 \%$ at a $5 \mu \mathrm{M}$ dose (Fig. 3A). As presented in Table I, a significant increase $(\mathrm{P}<0.001)$ in $\mathrm{G} 2 / \mathrm{M}$ phase at a $5 \mu \mathrm{M}$ dose for $48 \mathrm{~h}$, $24.65 \pm 0.70 \%$ cell population compared with $8.13 \pm 0.95 \%$ of control value, and simultaneously a significant decrease $(\mathrm{P}<0.001)$ in cell population from $62.40 \pm 1.65 \%$ of control value to $46.92 \pm 1.02 \%$ in cells in $\mathrm{G} 0 / \mathrm{G} 1$ phase at the same dose was observed. Furthermore, to validate the phenomenon of apoptosis, the involvement of apoptotic pathways was investigated in stevioside-treated HT-29 cells. 
Table I. Cell cycle and apoptosis ratios with various concentrations of stevioside on HT-29 cells.

\begin{tabular}{lccccc}
\hline Group & Concentration $(\mu \mathrm{M})$ & $\mathrm{G} 0 / \mathrm{G} 1(\%)$ & $\mathrm{S}(\%)$ & $\mathrm{G} 2 / \mathrm{M}(\%)$ & Apoptosis ratio $(\%)$ \\
\hline Stevioside & 0 & $62.40 \pm 1.65$ & $29.47 \pm 1.72$ & $8.13 \pm 0.95$ & $2.02 \pm 0.06$ \\
& 0.5 & $59.23 \pm 2.84$ & $30.25 \pm 1.62$ & $10.52 \pm 0.80^{\mathrm{a}}$ & $3.06 \pm 0.20^{\mathrm{a}}$ \\
& 1.0 & $56.80 \pm 2.10^{\mathrm{a}}$ & $31.37 \pm 1.12$ & $11.83 \pm 0.81^{\mathrm{b}}$ & $8.28 \pm 0.08^{\mathrm{b}}$ \\
& 2.5 & $52.68 \pm 2.35^{\mathrm{b}}$ & $29.43 \pm 3.54$ & $17.89 \pm 1.26^{\mathrm{c}}$ & $14.54 \pm 1.86^{\mathrm{b}}$ \\
& 5.0 & $46.92 \pm 1.02^{\mathrm{c}}$ & $28.43 \pm 1.26$ & $24.65 \pm 0.70^{\mathrm{c}}$ & $24.15 \pm 1.56^{\mathrm{c}}$ \\
\hline
\end{tabular}

${ }^{\mathrm{a}} \mathrm{P}<0.05,{ }^{\mathrm{b}} \mathrm{P}<0.01,{ }^{\mathrm{c}} \mathrm{P}<0.001$ vs. the untreated cells.
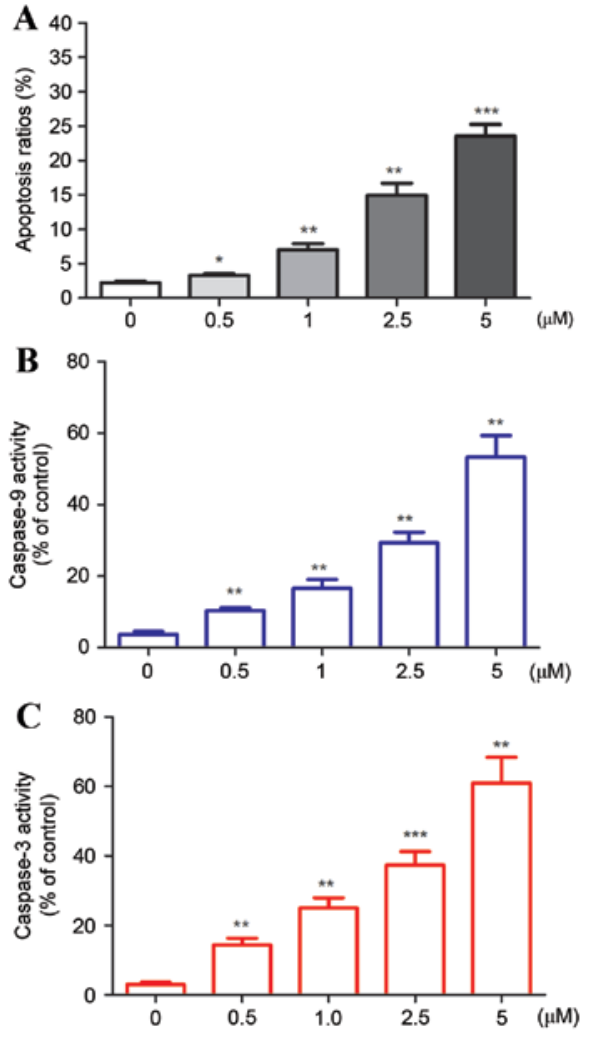

Figure 3. (A) Apoptotic effect of stevioside on HT-29 colon cancer cells, (B) effect of stevioside on caspase-9 activity, (C) Effect of stevioside on caspase- 3 activity. Data is shown as the mean \pm standard deviation. ${ }^{*} \mathrm{P}<0.05$, ${ }^{* *} \mathrm{P}<0.01,{ }^{* * *} \mathrm{P}<0.001$

Stevioside increased caspase-9 and -3 activity in HT-29 cells. Furthermore, to confirm the apoptotic effect of stevioside on HT-29 cells, caspase- 9 and caspase-3 activities were assessed as indicators of apoptosis (23). Significant increases in caspase-9 ( $\mathrm{P}<0.01$; Fig. 3B) and caspase-3 ( $\mathrm{P}<0.01$; Fig. 3C) activities were observed in stevioside-treated HT-29 cells in a dose-dependent manner subsequent to $48 \mathrm{~h}$ of treatment. A significant increase in the activities of caspase-9 and caspase-3, to $\sim 53(\mathrm{P}<0.01)$ and $61 \%(\mathrm{P}<0.01)$, respectively, were observed subsequent to treatment with $5 \mu \mathrm{M}$ stevioside, confirming their involvement in inducing cell apoptosis.

Stevioside increased ROS level and decreased $\triangle \Psi m$ level in HT-29 cells. Fig. 4A and B shows the intracellular ROS and $\Delta \Psi \mathrm{m}$ levels in HT-29 cells subsequent to treatment with stevioside at $48 \mathrm{~h}$. ROS has been reported to be an apoptosis inducer and the level of ROS was measured using $\mathrm{H}_{2}$ DCF-DA, a fluorescent dye (24). Furthermore, altered $\Delta \Psi \mathrm{m}$ has been hypothesized to be a significant event of apoptosis (25) and the level of this event was assessed using $\mathrm{DiOC}_{6}(3)$, a voltage-dependent and mitochondria-specific fluorescent dye, in stevioside-treated HT-29 cells. As shown in Fig. 4A and $\mathrm{B}$, intracellular levels of ROS increased and $\Delta \Psi \mathrm{m}$ levels decreased dose-dependently in HT-29 cells subsequent to stevioside treatment. The maximum increase in ROS level was $\sim 58 \%$ and maximum decrease in $\Delta \Psi \mathrm{m}$ level was $\sim 29 \%$ in HT-29 cells treated with $5 \mu \mathrm{M}$ stevioside. The involvement of ROS in inducing apoptosis in stevioside-treated HT-29 cells was therefore confirmed, and the contribution of underlying mitochondrial signaling pathways in the induction of apoptosis was indicated.

Stevioside increased the expression levels of ERK and p38 MAPK protein. ERK and p38 MAPK are involved in cell proliferation by regulating cell growth, oxidative stress and differentiation. The activation of MAPKs has been reported in a previous study (26). To verify the involvement of p38 MAPK and ERK in the apoptotic activity of stevioside in HT-29 cells, dose-dependent phosphorylation of p38 MAPK and ERK was monitored by western blotting. Fig. 5 demonstrates the increases in pERK and p-p38 MAPK levels at $5 \mu \mathrm{M}$ stevioside for $48 \mathrm{~h}$. Thus, the involvement of ERK and the p38 MAPK pathway in stevioside-induced apoptosis is indicated.

Stevioside-induced apoptosis in HT-29 cells was associated with ROS production and MAPK proteins. The HT-29 cells were treated with an ROS scavenger, NAC, to verify whether ROS is essential for stevioside-induced cell apoptosis. The results obtained showed an increase in HT-29 cell viability following NAC pretreatment, which is a clear indication of the role of ROS in apoptosis induction (Fig. 6A). Furthermore, to determine whether p38 MAPK and ERK are essential in inducing apoptosis in stevioside-treated cells, the cells were pretreated with an ERK inhibitor, PD98059, and a p38 MAPK inhibitor, SB203580, for $2 \mathrm{~h}$. Pretreatment with PD98059 and SB203580 in stevioside-treated cells exhibited a significant increase in the cell viability $(\mathrm{P}<0.05$ and $\mathrm{P}<0.01$, respectively, vs. treatment with stevioside alone), confirming that ERK and p38 MAPK are involved in ROS-mediated apoptosis in HT-29 cells treated with stevioside (Fig. 6B and $\mathrm{C}$, respectively). 

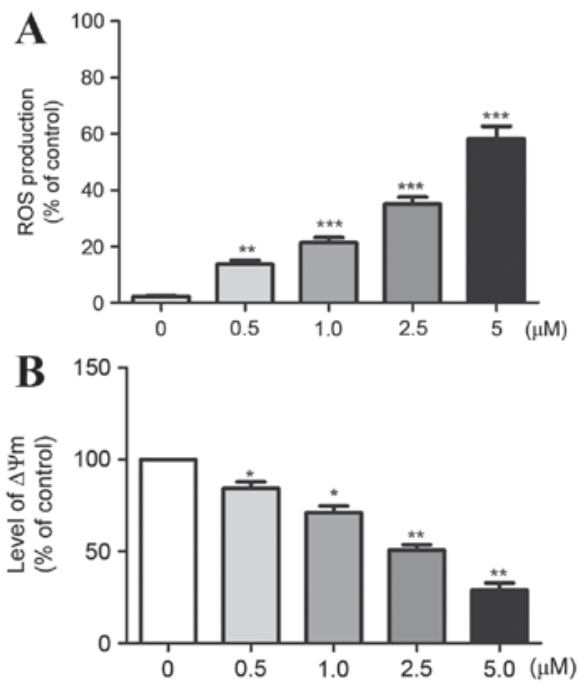

Figure 4. (A) Effect of stevioside on ROS production, (B) effect of stevioside on $\Delta \Psi \mathrm{m}$ level. Data are shown as the mean \pm standard deviation. ${ }^{*} \mathrm{P}<0.05$ ${ }^{* *} \mathrm{P}<0.01,{ }^{* * *} \mathrm{P}<0.001$. ROS, reactive oxygen species; $\Delta \Psi \mathrm{m}$, mitochondrial membrane potential.

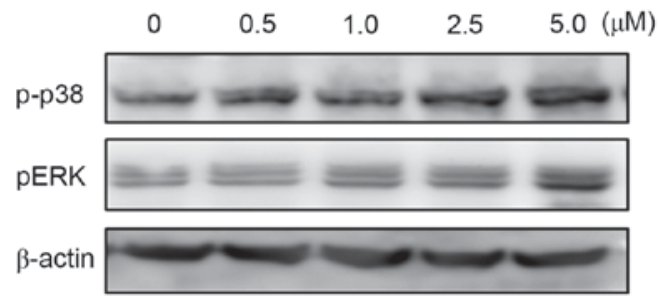

Figure 5. Regulation of p-p38 MAPK, pERK and $\beta$-actin expression in HT-29 cells upon stevioside treatment. p-p38 MAPK, phosphorylated P-38 mitogen-activated protein kinase pathway; pERK, phosphorylated extracellular signal-regulated kinases.

\section{Discussion}

The ability of natural products to reverse or suppress cancer development is well known (27). However, the exact mode of action of natural products remains unknown. In the search for novel anticancer molecules, the use of dietary phytochemicals as natural chemotherapeutic agents has been discussed previously (28). Stevioside is a type of dietary phytochemicals, which is known to possess anticancer properties (29). Nakamura et al (30) showed the antitumor activity of stevioside on 12-O-tetradecanoylphorbol-13-acetate-induced skin cancer. Furthermore, isosteviol, a hydrolysis product of stevioside, inhibited DNA polymerases and DNA topoisomerase II, which are potential cellular targets for oncotherapy (31). In accordance with previous studies, the treatment of stevioside at various doses, $0.5,1.0,2.5$ and $5.0 \mu \mathrm{M}$ for 24,48 and $72 \mathrm{~h}$ on colon cancer HT-29 cells resulted in decreased cell viability and increased cell cytotoxicity via MTT and LDH assay, respectively (Fig. 2).

Cell cycle and cell growth are well-regulated phenomena that are mediated by the checkpoints G0/G1 and G2/M between growth phases, and apoptosis or cell cycle arrest is initiated if DNA damage occurs or if DNA replication is not completed in the previous phase $(32,33)$. As reported previously, the anti-proliferative effect of various natural
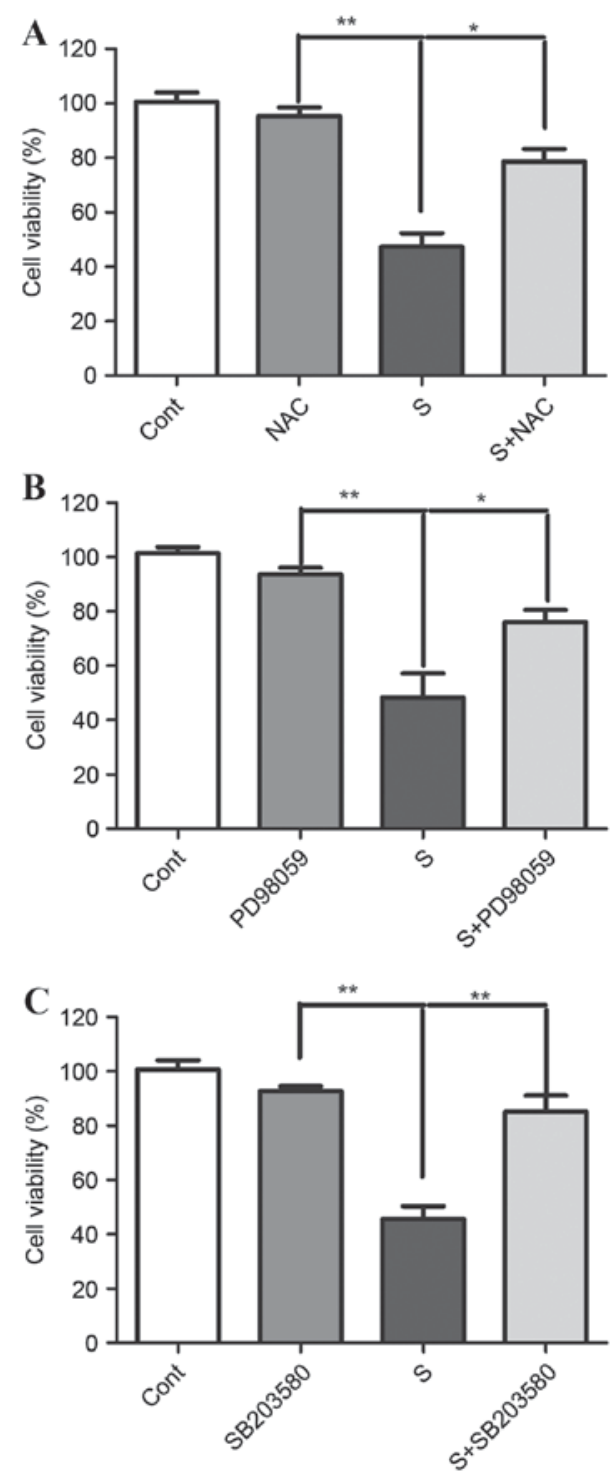

Figure 6. Growth inhibitory effect of stevioside on HT-29 cells subsequent to treatment with (A) NAC, an ROS scavenger, (B) the ERK inhibitor PD98059 and (C) the MAPK inhibitor SB203580. Data are shown as the mean \pm standard deviation. " $\mathrm{P}<0.05,{ }^{* *} \mathrm{P}<0.01$. S, stevioside; NAC, N-acetyl-L-cysteine; ROS, reactive oxygen species; ERK, extracellular signal-regulated kinases; MAPK, mitogen-activated protein kinase pathway.

phytochemicals was found to be associated with apoptosis in different cellular systems $(34,35)$. Therefore, to additionally identify whether the stevioside-induced antiproliferative effect on HT-29 cells was accompanied by apoptosis and cell cycle arrest, flow cytometry was performed subsequent to stevioside treatment at various doses for $48 \mathrm{~h}$, based on significant MTT and LDH results. The highest number of apoptotic cells was observed at a $5.0 \mu \mathrm{M}$ dose of stevioside (Fig. 3A). Furthermore, a significant reduction in cell numbers was observed in the G0/G1 phase in treated cells as compared to the control. An increase in the cell population was observed in the $\mathrm{G} 2 / \mathrm{M}$ phase compared with the control value indicating cell arrest in this phase (Table I).

The effect of stevioside on the human breast cancer MCF-7 cell line through various pathways including cell viability suppression, DNA synthesis inhibition and ROS-mediated apoptotic cell death has also been previously demonstrated (19). ROS 
is mainly produced by mitochondria and acts as a secondary messenger for various cellular processes, such as apoptosis and cell proliferation. Though the actual role of ROS remains unknown, it can be assumed that the constant production and removal of ROS is necessary to maintain and regulate the physiological balance of the cell $(36,37)$. In addition, elevated ROS have been revealed to be associated with the lowering of the $\Delta \Psi \mathrm{m}$ (38). Therefore, the present study aimed to correlate the induction of apoptosis with ROS production in stevioside-treated HT-29 cells. As shown in Fig. 4, ROS production increased and $\Delta \Psi \mathrm{m}$ decreased dose-dependently subsequent to stevioside treatment, suggesting that apoptosis was induced by an elevated ROS level. In agreement with this result, cells pretreated with NAC, an ROS scavenger, showed increased cell viability, confirming ROS-dependent apoptosis in HT-29 cells subsequent to stevioside treatment (Fig. 6). Additionally, the decrease in $\Delta \Psi \mathrm{m}$ suggests the involvement of mitochondrial apoptotic factors in the present study. Changes in $\Delta \Psi$ m may initiate cytochrome $c$ release from mitochondria, which may additionally activate caspase- 9 and caspase-3 (39). Thus, in the present study the enhanced level of caspase- 9 and caspase- 3 following stevioside treatment also verified the involvement of a mitochondrial-mediated intrinsic apoptotic pathway (Fig. 3).

Since ROS and caspase levels increased in stevioside-treated cells, the present study also assessed the expression of MAPK family members such as p38 and ERK. A wide range of extracellular signals may trigger MAPK pathways, which activates a cascade of signaling mechanisms. Extracellular stress is mainly responsible for $\mathrm{p} 38$ activation while mitogenic stimuli are responsible for ERK activation, which is involved in cell differentiation and proliferation $(40,41)$. The present study observed that in HT-29 cells the levels of phosphorylated p38 and ERK increased subsequent to incubation with stevioside for $48 \mathrm{~h}$ in a dose-dependent manner (Fig. 5). However, stevioside did not induce antiproliferative effects subsequent to pre-treatment with the inhibitors of p38 and ERK signaling pathways, suggesting that their pathways affect the cellular response to stevioside (Fig. 6).

In conclusion, the results of the present study showed that in stevioside-treated colon cancer HT-29 cells, ROS and MAPK serve critical roles in inducing apoptosis. Therefore, in the search for novel anticancer compounds, stevioside may be an interesting molecule to be additionally explored. Being natural in origin, stevioside may exhibit decreased toxicity compared with artificial chemotherapeutic drugs. However, the exact potential and mode of action of stevioside as anticancer drug require investigation.

\section{References}

1. Ferlay J, Soerjomataram I, Dikshit R, Eser S, Mathers C, Rebelo M, Parkin DM, Forman D and Bray F: Cancer incidence and mortality worldwide: sources, methods and major patterns in GLOBOCAN 2012. Int J Cancer 136: 359-386, 2015

2. Manoj G, Thampi BS, Leelamma S and Menon PV: Effect of dietary fiber on the activity of intestinal and fecal beta-glucuronidase activity during 1,2-dimethylhydrazine induced colon carcinogenesis. Plant Foods Hum Nutr 56: 13-21, 2001.

3. Gallagher DJ and Kemeny N: Metastatic colorectal cancer: From improved survival to potential cure. Oncology 78: 237-248, 2010

4. Morley KL, Ferguson PJ and Koropatnick J: Tangeretin and nobiletin induce G1 cell cycle arrest but not apoptosis in human breast and colon cancer cells. Cancer Lett 251: 168-178, 2007.
5. Kim JY, Hwang JH, Cha MR, Yoon MY, Son ES, Tomida A, Ko B, Song SW, Shin-ya K, Hwang YI and Park HR: Arctigenin blocks the unfolded protein response and shows therapeutic antitumor activity. J Cell Physiol 224: 33-40, 2010.

6. Parpinello GP, Versari A, Castellari M and Galassi S: Stevioside as a replacement of sucrose in peach juice: Sensory evaluation. Journal of Sensory Studies 16: 471-484, 2001.

7. Hanson JR and De Oliveira BH: Stevioside and related sweet diterpenoid glycosides. Nat Prod Rep 10: 301-309, 1993.

8. Gasmalla MAA, Yang R, Musa A, Hua X and Zhang W: Physico-chemical Assessment and Rebauidioside A. Productively of Natural Sweeteners (Stevia RebaudianaBertoni). J Food Nut Res 2: 209-214, 2014.

9. Brahmachari G, Mandal LC, Roy R, Mondal S and Brahmachari AK: Stevioside and related compounds-molecules of pharmaceutical promise: A critical overview. Arch Pharm (Weinheim) 344: 5-19, 2011.

10. Gregersen S, Jeppesen PB, Holst JJ and Hermansen K: Antihyperglycemic effects of stevioside in type 2 diabetic subjects. Metabolism 53: 73-76, 2004.

11. Chatsudthipong V and Muanprasat C: Stevioside and related compounds: Therapeutic benefits beyond sweetness. Pharmacol Ther 121: 41-54, 2009.

12. Wölwer-Rieck U, Tomberg W and Wawrzun A: Investigations on the stability of stevioside and rebaudioside a in soft drinks. J Agric Food Chem 58: 12216-12220, 2010.

13. Park HR, Furihata K, Hayakawa Y and Shin-ya K: Versipelostatin, a novel GRP78/Bip molecular chaperone down-regulator of microbial origin. Tetrahedron Lett 43: 6941-6945, 2002.

14. Son Y, Cheong YK, Kim NH, Chung HT, Kang DG and Pae HO: Mitogen-activated protein kinases and reactive oxygen species: How can ROS activate MAPK pathways? J Signal Transduct 2011: 792639, 2011.

15. Chang YC and Chuang LM: The role of oxidative stress in the pathogenesis of type 2 diabetes: From molecular mechanism to clinical implication. Am J Transl Res 2: 316-331, 2010.

16. Valko M, Leibfritz D, Moncol J, Cronin MT, Mazur M and Telser J: Free radicals and antioxidants in normal physiological functions and human disease. Int J Biochem Cell Biol 39: 44-84, 2007.

17. Torres $\mathrm{M}$ and Forman HJ: Redox signaling and the MAP kinase pathways. Biofactors 17: 287-296, 2003.

18. Winter-Vann AM and Johnson GL: Integrated activation of MAP3Ks balances cell fate in response to stress. J Cell Biochem 102: 848-858, 2007.

19. Paul S, Sengupta S, Bandyopadhyay TK and Bhattacharyya A: Stevioside induced ROS-mediated apoptosis through mitochondrial pathway in human breast cancer cell line MCF-7. Nutr Cancer 64: 1087-1094, 2012.

20. Martinez-Outschoorn UE, Lin Z, Trimmer C, Flomenberg N, Wang C, Pavlides S, Pestell RG, Howell A, Sotgia F and Lisanti MP: Cancer cells metabolically 'fertilize' the tumor microenvironment with hydrogen peroxide, driving the Warburg effect: Implications for PET imaging of human tumors. Cell Cycle 10: 2504-2520, 2011.

21. Lin JP, Yang JS, Chang NW, Chiu TH, Su CC, Lu KW, Ho YT, Yeh CC, Mei-Dueyang, Lin HJ and Chung JG: GADD153 mediates berberine-induced apoptosis in human cervical cancer Ca ski cells. Anticancer Res 27: 3379-3386, 2007.

22. Liu H, Xiao Y, Xiong C, Wei A and Ruan J: Apoptosis induced by a new flavonoid in human hepatoma HepG2 cells involves reactive oxygen species-mediated mitochondrial dysfunction and MAPK activation. Eur J Pharmacol 654: 209-216, 2011.

23. Mazumder S, Plesca D and Almasan A: Caspase-3 activation is a critical determinant of genotoxic stress-induced apoptosis. Methods Mol Biol 414: 13-21, 2008.

24. Tsai SC, Huang WW, Huang WC, Lu CC, Chiang JH, Peng SF, Chung JG, Lin YH, Hsu YM, Amagaya S and Yang JS: ERK-modulated intrinsic signaling and $\mathrm{G}(2) / \mathrm{M}$ phase arrest contribute to the induction of apoptotic death by allyl isothiocyanate in MDA-MB-468 human breast adenocarcinoma cells. Int J Oncol 41: 2065-2072, 2012.

25. Ly JD, Grubb DR and Lawen A: The mitochondrial membrane potential (deltapsi(m)) in apoptosis; an update. Apoptosis 8: 115-128, 2003

26. McCubrey JA, Lahair MM and Franklin RA: Reactive oxygen species-induced activation of the MAP kinase signaling pathways. Antioxid Redox Signal 8: 1775-1789, 2006. 
27. Jagtap S, Meganathan K, Wagh V, Winkler J, Hescheler J and Sachinidis A: Chemoprotective mechanism of the natural compounds, epigallocatechin-3-O-gallate, quercetin and curcumin against cancer and cardiovascular diseases. Curr Med Chem 16: 1451-1462, 2009.

28. Khan MK, Ansari IA and Khan MS: Dietary phytochemicals as potent chemotherapeutic agents against breast cancer: Inhibition of NF- $\kappa$ B pathway via molecular interactions in rel homology domain of its precursor protein p105. Pharmacogn Mag 9: 51-57, 2013.

29. Chatsudthipong V and Muanprasat C: Stevioside and related compounds: Therapeutic benefits beyond sweetness. Pharmacol Ther 121: 41-54, 2009.

30. Nakamura Y, Sakiyama S and Takenaga K: Suppression of syntheses of high molecular weight nonmuscle tropomyosins in macrophages. Cell Motil Cytoskeleton 31: 273-282, 1995.

31. Mizushina Y, Akihisa T, Ukiya M, Hamasaki Y, Murakami-Nakai C, Kuriyama I, Takeuchi T, Sugawara F and Yoshida H: Structural analysis of isosteviol and related compounds as DNA polymerase and DNA topoisomerase inhibitors. Life Sci 77: 2127-2140, 2005.

32. Ferreira CG, Epping M, Kruyt FA and Giaccone G: Apoptosis: Target of cancer therapy. Clin Cancer Res 8: 2024-2034, 2002.

33. Castedo M, Perfettini JL, Roumier T and Kroemer G Cyclin-dependent kinase-1: Linking apoptosis to cell cycle and mitotic catastrophe. Cell Death Differ 9: 1287-1293, 2002.
34. Chetram MA, Bethea DA, Odero-Marah VA, Don-Salu-Hewage AS, Jones KJ and Hinton CV: ROS-mediated activation of AKT induces apoptosis via pVHL in prostate cancer cells. Mol Cell Biochem 376: 63-71, 2013.

35. Efferth T, Giaisi M, Merling A, Krammer PH and Li-Weber M: Artesunate Induces ROS-mediated apoptosis in doxorubicin-resistant T leukemia cells. PLoS One 2: e693, 2007.

36. Dickinson BC and Chang CJ: Chemistry and biology of reactive oxygen species in signaling or stress responses. Nat Chem Biol 7: 504-511, 2011.

37. Tochhawng L, Deng S, Pervaiz S and Yap CT: Redox regulation of cancer cell migration and invasion. Mitochondrion 13: 246-253, 2013

38. Franco R and Cidlowski JA: Apoptosis and glutathione: Beyond an antioxidant. Cell Death Differ 16: 1303-1314, 2009.

39. Gollapudi S, McCormick MJ and Gupta S: Changes in mitochondrial membrane potential and mitochondrial mass occur independent of the activation of caspase- 8 and caspase-3 during CD95-mediated apoptosis in peripheral blood T cells. Int J Oncol 22: 597-600, 2003.

40. Kyriakis JM and Avruch J: Mammalian mitogen-activated protein kinase signal transduction pathways activated by stress and inflammation. Physiol Rev 81: 807-869, 2001.

41. Chung HS, Park SR, Choi EK, Park HJ, Griffin RJ, Song CW and Park H: Role of sphingomyelin-MAPKs pathway in heat-induced apoptosis. Exp Mol Med 35: 181-188, 2003. 